NBER WORKING PAPER SERIES

\title{
URBAN GROWTH AND HOUSING SUPPLY
}

\author{
Edward L. Glaeser \\ Joseph Gyourko \\ Raven E. Saks \\ Working Paper 11097 \\ http://www.nber.org/papers/w11097
}

\section{NATIONAL BUREAU OF ECONOMIC RESEARCH \\ 1050 Massachusetts Avenue \\ Cambridge, MA 02138 \\ January 2005}

We are grateful to the Taubman Center for State and Local Government at Harvard University and the Research Sponsors Program of the Zell/Lurie Real Estate Center at The Wharton School of the University of Pennsylvania for financial support. We thank the editor (Gilles Duranton), the referees, Kathy O'Regan, Jesse Shapiro, and session participants at the Winter 2004 APPAM meetings for helpful comments. Naturally, we are responsible for any remaining errors. The views expressed herein are those of the author(s) and do not necessarily reflect the views of the National Bureau of Economic Research.

(C) 2005 by Edward L. Glaeser, Joseph Gyourko, and Raven E. Saks. All rights reserved. Short sections of text, not to exceed two paragraphs, may be quoted without explicit permission provided that full credit, including $\odot$ notice, is given to the source. 
Urban Growth and Housing Supply

Edward L. Glaeser, Joseph Gyourko, and Raven E. Saks

NBER Working Paper No. 11097

January 2005

JEL No. R0

\begin{abstract}
$\underline{\text { ABSTRACT }}$
Cities are physical structures, but the modern literature on urban economic development rarely acknowledges that fact. The elasticity of housing supply helps determine the extent to which increases in productivity will create bigger cities or just higher paid workers and more expensive homes. In this paper, we present a simple model that provides a framework for doing empirical work that integrates the heterogeneity of housing supply into urban development. Empirical analysis yields results consistent with the implications of the model that differences in the nature of house supply across space are not only responsible for higher housing prices, but also affect how cities respond to increases in productivity.
\end{abstract}

Edward L. Glaeser

Department of Economics

315A Littauer Center

Harvard University

Cambridge, MA 02138

and NBER

eglaeser@harvard.edu

Joseph Gyourko

The Wharton School

University of Pennsylvania

gyourko@wharton.upenn.edu

Raven E. Saks

Harvard University

saks@fas.harvard.edu 


\section{Introduction}

The modern literature on urban growth and economic geography generally ignores housing supply. In the index of the recent Oxford Handbook of Economic Geography, the subject of housing only appears in John Kain's essay on racial and economic segregation (Kain (2000)). The subject "real estate" does not appear at all. In this paper, we argue that it is impossible to understand many aspects of urban dynamics without understanding housing supply, and that it is difficult to think sensibly about real estate in many contexts without understanding the urban equilibrium which determines the price and quantity of housing.

This observation is not new, as the leading early urban economists including William Alonso (1964), John Kain (1962, 1968), Edwin Mills (1967), and Richard Muth (1969) were keenly focused on the interplay between housing markets and the urban economy. However, in the years since their seminal work, real estate and urban economics increasingly have become separate subject areas. Virtually none of the papers on urban growth that have appeared in general interest economics journals over the past 20 years mention the supply of housing. At the same time, the real estate literature has focused on a variety of other issues such as housing as a financial asset that tend to be orthogonal to housing's larger role in economic geography.

In this paper we re-unite the topics of urban and real estate by exploring the role that housing supply has played in mediating urban dynamics over recent decades. Our particular interest is how the nature of supply impacts the form that urban success takes. That is, how do differences in supply-side conditions across areas help determine whether demand shocks translate primarily into changing prices or quantities? While our empirical analysis at the metropolitan area level leads us away from the micro-level issues such as segregation and bid-rent patterns that were discussed by the authors cited above, our intellectual debt to them is clear. 
Figure 1 illustrates the key issues. If a city's housing supply is relatively elastic, we should expect an outward shift in demand to result in an increase in population, while the corresponding increase in housing prices should be relatively modest (see point A). Even in the face of a major positive demand shock, unfettered new supply should prevent the price of housing from rising much above construction costs. Moreover, new construction helps ensure that an increase in labor demand will not lead to large increases in wages because an elastic supply of homes helps create an elastic supply of labor. However, if housing supply is inelastic, then positive shocks to urban productivity will have little impact on new construction or the urban population. Because the number of homes does not increase significantly, housing prices must rise (point B). Wages should rise as well, both because firms have become more productive and because workers must be compensated for rising housing prices. In contrast, if an amenity level rises in a city with an inelastic housing supply, then nominal wages (which are determined by labor demand) will be unchanged and housing prices will rise, implying a decline in real wages.

Our analysis begins in Section II with a review of the extraordinarily tight link between population and the stock of housing across areas within the United States. The number of people in an area can be thought of as a multiple of the number of housing units. Moreover, this relationship is strong in term of growth rates, not just in the levels. To break the tight link between the number of homes and the number of people, it would have to be true that there is significant variation in vacancy rates or household size over space and time. While there certainly is variation in these variables, it has not been large enough to create meaningful changes in population across cities without commensurate changes in the size of the local housing stock.

The correlation between housing supply and population change provides a necessary, but not sufficient, element of the case that the nature of the supply of housing is important for understanding urban dynamics. In principle, city growth could be completely determined by other variables, with the housing supply simply responding to those factors. Consequently, we discuss particular features of the housing supply that have an exogenous impact on the course of economic growth in cities. One such factor is the 
durability of housing, which implies that cities will lose housing units only very gradually after they receive a negative shock. Recent research by Glaeser and Gyourko (2005) examines declining cities and reports much evidence that urban decline is mediated by durable housing. In this paper we provide additional evidence on the durability of housing, documenting that net losses from a city's housing stock almost never exceed $1 \%$ per year over decade-length periods.

Another increasingly important aspect of the housing supply that has the potential to change the pattern of economic growth in cities is land use policy. Following Saks (2004) and Glaeser, Gyourko and Saks (2005), we argue that housing supply has become very inelastic in some places because of restrictive zoning and other land use regulations. Section III presents a simple model to establish a framework for our empirical work that integrates heterogeneity of the housing supply into urban change studies. In doing so, the model formalizes the observation that shocks to places with more inelastic housing supply will have bigger impacts on wage and house price growth and smaller impacts on population growth.

Section IV provides empirical evidence of the importance of the housing supply in metropolitan areas across the United States. Using proxies for the severity of restrictions on new construction, we show that in places where land use regulation is less severe, the population response to positive labor demand shocks is stronger. As high levels of land use regulation restrict population growth, housing prices and ultimately wages are kept high. Thus, the housing supply is important not only for understanding changes in population within metropolitan areas, but also changes in prices within those areas as well. A brief conclusion summarizes our results and discusses potential avenues for future research.

\section{Stylized Facts on Housing and Urban Dynamics}

Correlations between the Housing Stock and Urban Growth 
The deep connection between urban change and the housing stock is clearly evident in the strong correlation between population levels and housing units. The top panel of Table 1 reports the correlation between the logarithm of the number of housing units and the logarithm of the population in every decade between 1970 and 2000 in the 316 metropolitan areas of the continental United States. The correlations are quite tight, with an $\mathrm{R}^{2}$ of .99 in each regression. Not only is the fit of the relationship almost perfect, but the estimated coefficients are remarkably close to one, ranging from 0.981 to 0.997 across the census years.

Of course, a tight correlation between population and housing units at a point in time does not necessarily imply that changes in population and changes in the housing stock also line up perfectly. To examine this issue, the bottom panel of Table 1 reports the correlations between the change in the logarithm of population and the change in the logarithm of the number of housing units. While the point estimates and $\mathrm{R}^{2} \mathrm{~s}$ are below those seen in the cross-section, they still reflect quite strong relationships. These findings suggest that the overwhelming variation in population is accomplished through changing the number of units, not in changing the number of people per unit. Nevertheless, for completeness we next discuss the reasons why population might differ from the housing stock—namely, vacancy rates and household size.

\section{Vacancy Rates and Changing Household Size}

The number of people in an area equals the number of housing units times the number of people per housing unit. There are two ways in which the number of people per housing unit can change. First, the number of people in an occupied unit can grow or contract. Second, the vacancy rate-that is, the share of housing units that are unoccupied--can change. In principle, if either the vacancy rate or household size is sufficiently flexible, then the stock of housing might not be so tightly linked with the size of the population.

Examining the distribution of vacancy rates across metropolitan areas in 1990 reveals that changes in vacancies are not likely to be a dominant explanation of changes in population 
growth. The mean residential vacancy rate across our sample of metropolitan areas is $9.1 \%$, with the standard deviation being $5.4 \%$. There is about a 10-percentage point difference between the $14.8 \%$ vacancy rate for the area in the $90^{\text {th }}$ percentile of the distribution and the $4.9 \%$ rate for the area in the $10^{\text {th }}$ percentile of the distribution. Thus, if a market changed from being one of the one-tenth least vacant locations in the nation to one of the one-tenth most vacant locations, the total decline in population (holding people per occupied unit constant) would be $9.9 \%$. In growing areas especially, vacancy rates are already fairly low, so there is little chance that decreases in vacancy rates could account for population growth in those places.

Figure 2 provides additional evidence that changes in city populations are unlikely to have been achieved through changes in vacancy rates. While there is a negative relationship between the growth rate of population from 1990 to 2000 and the change in the vacancy rate over the same time period, a $0.1 \log$ point increase in population is associated with only a 0.8 percentage point decrease in vacancy rate. This magnitude implies that as a city grows by 10 percent, that city's vacancy rate would decline by eight-tenths of one percent. Furthermore, the $\mathrm{R}^{2}$ of the reverse regression reveals that only $13 \%$ of changes in population can be explained by changes in vacancy rates during this decade. ${ }^{1}$ Thus, population growth in cities is not likely to be achieved solely or even largely through changes in the fraction of occupied housing units.

Even if the amount of occupied housing remains the same, changes in the local population could occur if the number of people per household changed. For example, rising housing prices might cause larger households to crowd into smaller homes, thus weakening the link between the total population and the size of the housing supply. ${ }^{2}$ Over the past thirty years, the average number of people per housing unit has declined as families have become smaller. The average number of people in each occupied housing

\footnotetext{
${ }^{1}$ Further evidence suggesting that vacancy rates do not play a large role in urban dynamics can be found in Hwang and Quigley (2004), who find that local macroeconomic conditions such as income and unemployment do not have a significant impact on vacancy rates.

${ }^{2}$ Although in a very different context, the issue of 'crowding' was central to some of the early work in modern urban economics. In addition to the works cited above, see Kain and Quigley (1975) for an examination of crowding in the context of race and discrimination.
} 
unit in our sample of metropolitan areas fell from 3.15 in 1970 to 2.56 in 2000, with the bulk of that decline occurring in the first ten years (there were 2.75 people per household in 1980). ${ }^{3}$ These changes help to explain how the population in certain locations such as Detroit was able to decline more quickly than the housing stock during the 1970s. If the typical household size in an area shrank by the national average and if no new homes were built, the population in a metropolitan area could have fallen by as much as $13 \%$ in the 1970s. In contrast, declines in household size were substantially smaller in the 1980s and 1990s. Therefore, changes in household size cannot account for the changes in population we observe during these later decades.

The weak connection between household size and metropolitan area population is illustrated in Figure 3, which plots the relationship between the logarithms of these two variables in 2000. The relationship is statistically significant, but it is not economically important. The $\mathrm{R}^{2}$ from the underlying regression is only 0.06 , and the dispersion depicted indicates that there are many other factors driving population differences across cities besides differences in household size. In other words, relatively little growth or decline of city populations has occurred in recent decades that can be attributed to changes in household size. Because changes in the number of occupied housing units also cannot explain differences in city growth rates, growth must have been accommodated through changes in the total number of housing units.

\section{Urban Decline and Durable Housing}

Previous research by Glaeser and Gyourko (2005) contends that many features of declining cities can be understood only as the result of the durable nature of housing. Because housing is very slow to deteriorate, the elasticity of housing supply is very low in response to a decline in housing demand. One of the key predictions of the model in their paper is that cities grow more quickly than they decline.

\footnotetext{
${ }^{3}$ Household size is defined as the number of people living in households divided by the number of occupied housing units. The actual decline in household size is likely to have been larger than reported between 1970 and 1980 due to a change in the definition of the population living in group quarters (Ruggles and Brower, 2003).
} 
In this paper, we provide additional evidence pertaining to the durability of housing from the American Housing Survey $(A H S)$ and decennial Census. One useful gauge of the durability of homes is how rarely they disappear from the housing stock, which can be assessed using the panel structure of the $A H S$. We calculated the permanent loss rates of housing units using central city data from the national core files over the four two-year periods between 1985 and 1993. Every two years, between 1.3 and 1.8 percent of housing units either permanently exit the housing stock or suffer such severe damage as to render the units uninhabitable. These values suggest that the housing stock of a city is unlikely to decline by more than 1 percent per year or 10 percent per decade.

Low rates of housing destruction imply that the distribution of growth rates of the housing stock will be skewed to the left. In Table 2, we report data on the fastest and slowest growing cities during the 1970s, 1980s, and 1990s. The sample includes all cities with more than 100,000 residents at the beginning of each decade. We look at cities here instead of metropolitan areas because only central cities have experienced declines in demand during the past several decades. Even in metropolitan areas like Detroit, the demand for housing in the suburbs has increased over time.

Some cities obviously have had the ability to expand their housing stock extremely rapidly. Housing units in Las Vegas grew by approximately 50\% in both the 1980s and the 1990s. The stock of units in Colorado Springs grew by more than $60 \%$ during the 1970s. While there seems almost no upper bound on growth, declines rarely exceed $10 \%$ of the beginning of decade stock. Over the entire 30-year period, in only five cases did a city lose $11 \%$ or more of its housing stock in a single decade: St. Louis in the 1970s ($16.5 \%)$, Detroit in both the 1970s and 1980s, (-11.5\% and 14\%, respectively), and Gary and Newark in the $1980 \mathrm{~s}$ (-14.5\% and $-16.9 \%$, respectively). This lower bound on the decline in housing units is consistent with the annual rate of housing loss of no more than $1 \%$ calculated just above using the $A H S$. In addition, the biggest population declines have only been modestly more severe than the corresponding changes in the housing stock (see Glaeser and Gyourko (2005)). 
In summary, many of America's declining cities have housing prices that are too low to justify new construction. To understand the population and employment dynamics of this group, it is particularly important to recognize the key role played by durability in rendering housing supply very inelastic in these places. Because many of the ramifications of this issue are explored in great detail in Glaeser and Gyourko (2005), the remainder of this paper will focus on the impact of the housing supply in areas with high or rising housing demand.

\section{Housing Supply and Urban Dynamics: An Empirical Framework}

To illustrate the role of the housing supply in urban housing and labor markets, we consider an economy composed of many metropolitan areas, each denoted by " $j$ ". Following much of the urban growth literature, we assume that workers are homogeneous. Indifference across metropolitan areas implies that all workers must receive a real reservation utility equal to $\underline{U}$ in every location. Utility in each location equals $C_{j}+W_{j}-R_{j}$, where $C_{j}$ is a city-specific amenity flow consumed by residents, $W_{j}$ is the city-specific wage paid to workers, and $R_{j}$ is the cost of housing in city $j$.

Because average transportation costs do not vary significantly across metropolitan areas, we simplify the algebra by abstracting from that feature of the urban landscape. ${ }^{4}$

Together, our assumptions imply the familiar equilibrium relationship of $\underline{U}+R_{j}=W_{j}+C_{j}$.

To capture labor demand, we assume that a distribution of tasks within the city can be indexed by productivity. Specifically, productive tasks are characterized by an exponential distribution, so that the number of tasks with productivity greater than $W_{j}$ is $e^{\alpha\left(A_{j}-W_{j}\right)}$. The parameter $\mathrm{A}_{\mathrm{j}}$ reflects the level of productivity in each location, with a

\footnotetext{
${ }^{4}$ According to the 2000 Census, the average commuting time across all metropolitan areas (defined as MSAs or CMSAs) was 23 minutes with a standard deviation of only 3 minutes. Furthermore, more than $85 \%$ of the areas had an average commuting time between 20 and 30 minutes.
} 
higher value implying that a larger number of tasks have productivity greater than $W_{j}$. At a given wage, productive opportunities will be exploited to the point where the output of the marginal activity equals the wage. Thus, total labor demand is determined by $\log \left(N_{j}\right)=\alpha A_{j}-\alpha W_{j}$, where $N_{j}$ denotes city employment.

We close the system by characterizing the housing market. There are several issues that make housing complex. Because housing is durable, the supply of housing will be perfectly inelastic in areas where rents are not high enough to justify new construction. If the demand for housing is sufficiently high, then the price of housing will be determined by the cost of new construction. This cost is composed of the physical cost of new construction plus any costs related to regulatory barriers or other limits on housing supply. We make the simplifying assumption that the cost of new construction is based on a fixed, city-specific factor $\left(K_{j}\right)$ and the density of housing units that already exist in the area. This dependence on density is meant to capture the myriad ways that housing supply regulations can increase the cost of construction, and will be discussed in more detail in Section IV. Assuming that the number of housing units is equal to the size of the population, the cost of construction in each city becomes $K_{j}+\delta \log \left(N_{j} / L_{j}\right)$, where $L_{j}$ reflects the land area in the city. ${ }^{5}$ A high value of $\delta$ means that a given increase in the city's population density is associated with a large increase in construction costs, which implies that the housing supply is more inelastic. To convert housing prices into rent, we assume that rent equals a fixed capitalization rate (denoted $\rho$ ) times construction costs. We let $H_{j}$ denote housing prices in the city, so that $R_{j}=\rho H_{j}$.

Combining the three separate markets shows that wages, rents and population in a nondeclining city are determined by the following equations:

\footnotetext{
${ }^{5}$ The assumption that the number of housing units equals the size of the labor force implies that there is no commuting between locations. Because the unit of analysis in our empirical work is the metropolitan area (which defines labor market areas in the United States), the degree of inter-area commuting is small. The 2000 Census reports that $90 \%$ of all employed residents of metropolitan areas worked in the same area in which they lived.
} 
(1) $\log \left(N_{j}\right)=\frac{\alpha A_{j}+\alpha C_{j}+\alpha \rho \delta \log \left(L_{j}\right)-\alpha \underline{U}-\alpha \rho K_{j}}{1+\alpha \rho \delta}$,

(2) $W_{j}=\frac{\alpha \rho \delta A_{j}+\underline{U}+\rho K_{j}-C_{j}-\rho \delta \log \left(L_{j}\right)}{1+\alpha \rho \delta}$, and

(3) $H_{j}=\frac{\alpha \delta A_{j}+\alpha \delta C_{j}+K_{j}-\delta \log \left(L_{j}\right)-\alpha \delta \underline{U}}{1+\alpha \rho \delta}$.

While our empirical analysis below focuses on productivity shocks, the comparative statics associated with a change in productivity $\left(A_{j}\right)$ or a change in the attractiveness of an area $\left(C_{j}\right)$ are summarized in Table 3 . If an area becomes more productive, then population, wages and housing prices all increase. If an area becomes more attractive, then housing prices and population will rise, but wages will fall.

Next we derive implications for the dynamic behavior of these variables by considering exogenous variation in the level of productivity or amenities. To be specific, we assume that $A_{j, t+1}-A_{j, t}=\sum_{k} \beta_{A}^{k} X_{j, t}^{k}+\varepsilon_{j, t}^{A}$ and $C_{j, t+1}-C_{j, t}=\sum_{k} \beta_{C}^{k} X_{j, t}^{k}+\varepsilon_{j, t}^{C}$, where $X_{j, t}^{k}$ are

city-specific characteristics at time t. One example of a component of $X_{j, t}^{A}$ is the skill composition of the city. An increase in the average education of the labor force will cause productivity, and thus $\mathrm{A}_{j, t}$ to rise. Substituting these expressions into equations (1)(3) and assuming that all other factors remain constant over time, the expressions for changes in population, wages and housing prices become:
(1') $\log \left(\frac{N_{j, t+1}}{N_{j, t}}\right)=I^{N}+\frac{\alpha}{1+\alpha \rho \delta} \sum_{k}\left(\beta_{A}^{k}+\beta_{C}^{k}\right) X_{j, t}^{k}+\frac{\alpha}{1+\alpha \rho \delta}\left(\varepsilon_{j, t}^{A}+\varepsilon_{j, t}^{C}\right)$
(2') $W_{j, t+1}-W_{j, t+1}=I^{W}+\frac{\alpha \rho \delta}{1+\alpha \rho \delta} \sum_{k}\left(\beta_{A}^{k}-\frac{\beta_{C}^{k}}{\alpha \rho \delta}\right) X_{j, t}^{k}+\frac{\alpha \rho \delta}{1+\alpha \rho \delta} \varepsilon_{j, t}^{A}-\frac{1}{1+\alpha \rho \delta} \varepsilon_{j, t}^{c}$
(3') $H_{j, t+1}-H_{j, t}=I^{H}+\frac{\alpha \delta}{1+\alpha \rho \delta} \sum_{k}\left(\beta_{A}^{k}+\beta_{C}^{k}\right) X_{j, t}^{k}+\frac{\alpha \delta}{1+\alpha \rho \delta}\left(\varepsilon_{j, t}^{A}+\varepsilon_{j, t}^{C}\right)$ 
where $I^{i}$ for $\mathrm{i}=\mathrm{N}, \mathrm{W}, \mathrm{Q}$ are city-specific intercept terms that are constant over time. By assumption, the error terms $\varepsilon_{j, t}^{A}$ and $\varepsilon_{j, t}^{C}$ are mean zero and orthogonal to the $X_{j, t}^{k}$ terms.

Equations (1'), (2') and (3') describe the evolution of employment, wages and housing prices over time as a function of changes in productivity and consumer amenities. Given any $X_{j, t}^{k}$ variable that is uncorrelated with the error terms, we can estimate its effect on each of three dependent variables. ${ }^{6}$ The regression coefficients from that estimation then can be used to determine the values of $\delta$ and $\rho$. More specifically, any variable $X_{j, t}^{k}$ that leads to higher productivity will have an effect equal to those reported in the first column of Table 3 multiplied by $\beta_{A}^{k}$. Similarly, a $X_{j, t}^{k}$ that leads to an increase in consumption amenities will have an effect equal to those shown in the second column of Table 3 multiplied by a factor of $\beta_{C}^{k}$.

Closer examination of Table 3 reveals that $\delta$ and $\rho$ can be determined by calculating the ratio of the effects of productivity or amenity shocks on each of the outcome variables. For example, the effect of an increase in productivity on changes in housing prices is $\beta_{A}^{k} \frac{\alpha \delta}{1+\alpha \rho \delta}$, while the effect on changes in employment is $\beta_{A}^{k} \frac{\alpha}{1+\alpha \rho \delta}$. The ratio of these two coefficients is $\delta$. In the empirical analysis in Section IV, we will take advantage of this relationship to estimate variation in the value of $\delta$ across metropolitan areas. This method of estimating the elasticity of housing supply is particularly useful because the parameter $\alpha$ cancels out of the ratio. In principle, we can obtain unbiased estimates of $\delta$ even if there are systematic differences in productivity (or $\alpha$ ) across areas.

Our primary interest is in differences in $\delta$ across areas because they reflect variation in the elasticity of housing supply. Since the impact of productivity on population is decreasing in $\delta$ (see row 1 , column 1 of Table 3 ), we expect variables that raise

\footnotetext{
${ }^{6}$ In contrast with a dynamic growth model, predicted changes in housing prices, wages and population are not derived from adjustment to a long-run equilibrium. Rather, growth in these endogenous variables results from the assumption of exogenous changes in productivity and the value of amenities.
} 
productivity to be associated with larger increases in population in places where the housing supply is more elastic (i.e., where $\delta$ is low). Conversely, the effect of a productivity shock on wages and housing prices will be smaller in these areas. In places where housing supply is inelastic, we expect variables that raise productivity to be associated with relatively small increases in population, while the effects on wages and housing prices should be larger. The next section evaluates these predictions using data on metropolitan areas in the United States during the past twenty years.

\section{Estimation}

The unit of analysis in this section is a metropolitan area, as determined by 1999 Census Bureau definitions. ${ }^{7}$ These areas are defined expressly to encompass the entire labor market in each geographic location. If we were to focus instead on a smaller geographic unit, there would be several margins of adjustment that could alleviate the effect of housing supply constraints on any particular municipal jurisdiction. For example, both inter-area commuting and the expansion of the suburbs will cause housing supply constraints to be less binding in primary central cities. By considering the entire metropolitan area, we are able to observe the effect of the housing supply on the entire local housing and labor market.

The density of housing units is one obvious proxy for the elasticity of housing supply in a metropolitan area. There is little argument that the less available is land, the more difficult it is to build. The cost per square foot in multi-floor apartments is considerably higher than the cost per square foot to build a single-family detached homes, ${ }^{8}$ and congestion in a city can increase the difficulty of building in many other ways. However, places that are densely built generally also are locations where housing demand is relatively high. Thus, empirically it is difficult to separate out the effect of a limited housing supply in dense locations from higher housing demand.

\footnotetext{
${ }^{7}$ By aggregating all quantities from county-level data, we keep the geographic area encompassed by each metropolitan area constant over time.

${ }^{8}$ A primary reason that costs are lower in single-family buildings is that they require neither elevators nor interior/exterior stairwells for exit routes. Taller structures are more complex and require more expensive components and materials.
} 
Consequently, we use a measure of constraints on the housing supply that is constructed from data on state and local government land use policies. New construction should respond readily to increases in demand in areas where housing markets are largely unfettered. In contrast, new supply should be more inelastic in housing markets with binding development restrictions. Thus, differences in these regulations across locations reflect variation in the elasticity of housing supply. ${ }^{9}$ While some regulations may be implemented as a reaction to high housing demand, these policies almost certainly are more exogenous than reduced-form measures like urban density. In addition, we exclude from our analysis any policies such as growth controls that are likely to have been adopted directly in response to high growth.

One disadvantage to relying on land use regulations is that the regulatory environment has become exceedingly complex, thus making the severity of regulatory constraints difficult to measure. There are many possible avenues by which land use regulations can delay a construction project or halt it entirely. A few examples include zoning boards, city councils, the court system, public health officials, and wetlands conservation reviews. The very richness of the regulatory environment means that there is no one law or regulatory structure that would allow us to identify some metropolitan areas as being more onerously regulated compared with others. Moreover, it is not obvious that the rules on the books necessarily reflect the full extent of the zoning environment. ${ }^{10}$ While it is possible to use comparisons within a narrow geographic area to assess the impact of particular types of regulations (e.g., as in Katz and Rosen (1987)), such comparisons across metropolitan areas are much more difficult. However, measurement error of this type will have its standard effect of biasing our estimates of the effect of regulation towards zero. Hence, this empirical strategy only makes it more difficult to show that the nature of housing supply helps determines whether urban success is reflected more in higher quantitities (of people or homes) or in higher prices (of house values or incomes).

\footnotetext{
${ }^{9}$ A growing literature has documented a significant impact of these types of regulations on new construction and housing prices. For example, see Glaeser and Gyourko (2003), Glaeser, Gyourko, and Saks (2005), Malpezzi (1996), and Mayer and Somerville (2000).

${ }^{10}$ See Warner and Molotch (2000) for some convincing examples.
} 
We assess the strength of the regulatory environment in each metropolitan area using evidence from two surveys of land use regulation. The first is the Wharton land use control survey conducted by Linneman, et. al. (1990) that documents various constraints on residential development for 60 metropolitan areas. Because the laws themselves may not be all that informative, we use information on the length of time needed for permits to be processed and other broad measures of the severity of the regulatory environment. ${ }^{11}$ The second survey we use is a study of statewide regulations carried out by the American Institute of Planners (1976). Although local governments control most zoning and land use policies, states can influence residential development in a variety of ways. For example, they can restrict development in certain areas, require municipalities to implement comprehensive land-use planning strategies, and require developers to file environmental impact statements. An additional benefit to considering statewide regulations is that they are more likely to be unrelated to local idiosyncratic factors that influence housing demand in individual metropolitan areas. ${ }^{12}$

For each survey, we create an index of housing supply regulation that is normalized to have a mean of zero and a standard deviation of one. The final regulatory index is a simple average of these two component indexes. It is scaled to have a mean of zero, a standard deviation of one, and is increasing in the amount of regulation. Despite the breadth of the regulations used to compile this index, it does not describe all aspects of the elasticity of housing supply. Other factors such as congestion costs and the availability of vacant land also contribute to differences in the supply of housing. To the extent that these factors are correlated with the severity of housing supply regulation, our

\footnotetext{
${ }^{11}$ To be specific, the six survey questions we use are: the average length of time for re-zoning permits to be approved, the average length of time for subdivision permits to be approved, the fraction of zoning applications approved, a rating of the adequacy of the provision of infrastructure for growth needs, a rating of the importance of regulation in the development process, and the amount of impact fees per housing unit.

12 The specific regulations that make up this index are: comprehensive land use planning, coastal zone management plans, wetlands management regulations, floodplain management, designation of some locations as "critical" for land use regulation, enabling legislation for "new towns," requirement for environmental impact statements, and regulations preempting local regulations for "developments of greater than local impact."
} 
estimates will reflect the effect of having an inelastic housing supply in general, rather than the impact of regulation alone.

We begin by estimating equations suggested by the expressions (1'), (2') and (3'), where changes in the logarithm of population, per capita income and housing prices are regressed on metropolitan-level characteristics that predict economic growth (i.e., variables that belong in the set of $X_{j, t}^{k}$ ). The first predictor of growth considered is based on the industrial composition of each metropolitan area. Following Bartik (1991), we compute the employment share of each industry multiplied by the growth in the industry over the subsequent decade using county-level employment data at the two-digit SIC level from County Business Patterns. This measure predicts the extent to which employment in the area would have grown if the distribution of industries had stayed at its initial level and all firms in the industry had grown at exactly the same rate as the national average. The second predictor of local economic growth used is the initial share of adults with at least a bachelor's degree. A host of research documents a strong positive correlation between the skill level of a city's population and city growth in recent decades. We take this relationship as evidence that a larger amount of human capital in a city increases productivity (Glaeser and Saiz 2003, Moretti 2004a,b). ${ }^{13}$

The model in Section III predicts that positive shocks to the demand for housing will have a greater impact on population in areas with a more elastic housing supply, while wages and housing prices should be more heavily affected in more inelastic places. Therefore, our key empirical test will be to estimate the effect of these measures of productivity in heavily versus lightly regulated areas. Due to concerns about measurement error in the regulation index, we consider a dichotomous division rather than treating regulation as a continuous variable. We define metropolitan areas with a value of the regulation index greater than .45 to be locations with high regulation, which

\footnotetext{
${ }^{13}$ The level of educational achievement could be correlated with the severity of housing supply restrictions if more highly educated homeowners are more adept at controlling local politics to such ends. However, this will not bias us to find larger productivity effects. Rather, such a connection will make the impact of an increase in productivity smaller than it would have been otherwise, thereby biasing our estimated coefficient towards zero.
} 
comprises the highest third of the areas in our sample. Because there are a large number of areas clustered around the median, we believe this break point creates a more reasonable distinction between the more and less regulated areas. Dividing the areas around the median would arbitrarily categorize many similar communities into different groups. ${ }^{14}$

All regressions are estimated using decadal changes in population, wages and housing prices from 1980-1990 and 1990-2000. Observations from both decades are pooled together with a time dummy included to allow the intercept to differ across decades. Using 10-year changes means that our estimates are derived from the relatively long-run behavior of population, wages and housing prices. ${ }^{15}$ Housing prices are measured using the median housing price from the 1990 Census as a base and extrapolating this level to the years 1980 and 2000 with constant-quality price indexes published by the Office of Federal Housing Enterprise Oversight. ${ }^{16}$ We proxy for wages using income per capita in each metropolitan area as published by the Bureau of Economic Analysis.

The top panel of Table 4 reports estimates from specifications in which industrial labor demand is used as a proxy for productivity. The coefficients in the first row reflect the impact of the labor demand variable in the typical low-regulation metropolitan area, while those in the second row report the differential effect of this variable in an area with a highly-regulated housing supply. Stronger labor demand is associated with higher

\footnotetext{
${ }^{14}$ The results presented below do not change qualitatively if we choose alternate cutoffs to define highlyregulated areas or if we use this index as a continuous variable. However, the coefficient estimates are less precisely estimated, especially if a continuous measure of regulatory constraint is used. The data just are too noisy for us to be able to say anything meaningful about marginal changes in the constraint index.

${ }^{15}$ Due to time lags in the construction process, the short-run dynamics of these variables could be different. See Saks (2004) for a dynamic model of metropolitan area housing and labor markets.

${ }^{16}$ There are two advantages to using the OFHEO price indexes instead of Census data on median housing values or rents. Because the definition of metropolitan areas changed over time, median housing values in growing places will reflect a larger geographic area in 2000 than in prior decades. If the average housing price is lower in the outlying regions of a metropolitan area, the overall change in the median housing value will be biased downward. Another problem with using the Census data is that a portion of the change in housing values will reflect changes in the quality of housing, which could differ systematically across metropolitan areas. Using the OFHEO price indexes solves both of these problems because these indexes maintain constant definitions of metropolitan areas over time. Also, housing price changes are calculated from repeated sales of the same house, which avoids the bulk of the concern over changes in quality. Nevertheless, the results we present below are not materially different from those obtained when using median housing values instead of the OFHEO price indexes.
} 
population and income growth (significant at the $5 \%$ and $10 \%$ levels, respectively), but not higher house price appreciation. The coefficient of 1.28 indicates that this labor demand proxy strongly predicts population growth in low-regulation metropolitan areas. We cannot reject the null that population rises proportionately with predicted labor demand. A $1 \%$ increase in labor demand is also associated with $\$ 92$ higher real wage growth. This effect is equivalent to about $1 / 3$ of a standard deviation of changes in income, so the size of this effect is not large economically. Finally, stronger labor demand is not associated with higher house price appreciation in the typical market. The point estimate is negative, but it is both small in economic magnitude and not close to being statistically significant.

The impacts of the coefficients on the interaction between this labor demand variable and the degree of housing supply regulation are reported in the second row. These results indicate that more inelastically supplied markets have weaker population growth (column 1) and stronger house price appreciation (column 3) in response to an increase in labor demand (with both coefficients being significant at the $10 \%$ level), but there is no differential impact found for income. The magnitudes of the population growth and house price appreciation effects are economically important. The effect of labor demand on population growth is $50 \%$ lower in areas with highly regulated housing markets. An increase in labor demand had no substantial effect on housing prices in less regulated areas, but a $1 \%$ increase in labor demand in areas with strongly regulated housing supplies is associated with an increase in housing prices of $\$ 19,000$ per year. Compared with the standard deviation of changes in housing prices of $\$ 3,467$ in this sample, the magnitude of this effect is quite large.

The second panel of Table 4 reports results using the initial share of the adult population with a college degree to reflect productivity differences. The findings in the first row are qualitatively similar to those in the top panel, and show that stronger labor demand is associated with significantly higher population growth and real income growth, but not higher real house price appreciation. These estimates imply that metropolitan areas with $1 \%$ more college-educated workers experienced $.09 \%$ greater population growth in less 
regulated areas, an effect that is one tenth the size of the effect of predicted labor demand. The effect of education on wages is also somewhat smaller.

The interaction terms in the second row of this panel are all qualitatively consistent with the predictions of our model. In areas of high housing supply regulation, an increase in the share of college educated workers has an effect on wages that is 1.4 times as large as the effect in less regulated areas. The effect on changes in housing prices is also significantly greater than zero; a $1 \%$ increase in the share of college educated workers is associated with $\$ 237$ higher housing price growth per year, which is about equivalent to the standard deviation of changes in housing prices. Finally, the effect of education on population growth is $2 / 3$ smaller in highly regulated areas, although it is not statistically significant.

Even though noise in the measurement of severity of housing supply regulations and unobservable heterogeneity across locations make it difficult to estimate effects precisely from a cross-sectional comparison of metropolitan areas, these results are quite consistent with the implications of the model. Increases in productivity have a stronger impact on income and housing prices and a weaker impact on population growth in areas with more housing supply regulation.

To improve the precision of our estimates, we next combine both measures of productivity in a single regression and constrain the coefficients to be the same for both variables. In order to impose this restriction, both productivity variables are first normalized to have a mean of zero and a standard deviation of one. The results from this specification are reported in the bottom panel of Table 4. As before, stronger demand is associated with higher population and income growth in the typical market with less housing supply regulation, but increases in productivity have no statistically or economically significant effect on housing prices. The interaction terms show that highly-regulated areas have significantly less population growth in response to an increase in labor demand, while housing prices are significantly higher. Real incomes also are higher, but that effect is significant only at the $18 \%$ level. Again, these results 
are all qualitatively consistent with the predictions of the model and the magnitudes are considerable: an increase in productivity has triple the effect on population growth in less regulated areas, while its effect on housing prices is $40 \%$ smaller.

Next, we use these coefficient estimates from the bottom two rows of Table 4 to infer values of the parameters of the model. If we assume that our labor demand and human capital variables operate solely by increasing productivity and not by increasing amenities, then comparing the coefficients across equations provides back-of-theenvelope estimates of $\delta$ and $\rho$. As can readily be determined by forming the ratio of the formulae in the $2^{\text {nd }}$ and $3^{\text {rd }}$ rows of column one in Table 3 , the ratio of the coefficients in the income and housing regressions gives us an estimate of $\rho$, the extent to which higher housing prices translate into higher user costs of housing. When using both productivity variables combined, the estimates of $\rho$ are 0.22 in low-regulation areas and .11 in high-regulation areas. ${ }^{17}$

The value of $\delta$ can be inferred by the ratio of the coefficient on productivity in the house price growth regression to that in the population growth regression (i.e., compute the ratio of the term in the third row of column one of Table 3 to that in the first row of the first column). The implied values of $\delta$ are 50,781 in low-regulation areas and 625,079 in high-regulation locations. The economic interpretation of these numbers is that they reflect the amount that housing prices rise with a one log point (approximately 100 percent) increase in the population density of the metropolitan area. Thus, an estimated value of $\delta$ equal to 600,000 means that if the density of the area rises by 10 percent, housing prices will rise by about $\$ 60,000$. From our perspective, the important point is the vast difference between the high and low regulation areas. In the typical lowregulation metropolitan area, a 10 percent increase in population appears to raise housing costs by only about $\$ 5,000$. In high regulation areas, the same percentage change in population raises housing costs by $\$ 60,000$, or more than ten times as much. Thus, the

\footnotetext{
${ }^{17}$ In terms of gauging the sensibility of these results, the estimate for high-regulation locations are in line with user cost estimates reported by Poterba (1992). User costs do change over time for a variety of reasons, but the 0.22 estimate is high compared to all calculations of which we are aware.
} 
impact of an increase in productivity in highly-regulated metropolitan areas appears to be substantially stronger.

A more statistically precise way to estimate $\delta$ is to combine the equations in a joint system and restrict $\rho$ to some reasonable value. We set $\rho=0.15$ and estimate the system of equations constraining the effects of both productivity shocks to be the same. ${ }^{18}$ In low-regulation areas, $\delta=61,519$ (s.e. $=62,306$ ), while it equals 525,891 (s.e. $=328,017$ ) in high-regulation areas. While we again find large differences between low and highregulation areas, the estimates are imprecise enough that we cannot reject the hypothesis that the housing supply elasticities are equal in the two areas. In future work, we hope to explore other methods that will allow us to estimate these coefficients more precisely. ${ }^{19}$

\section{Conclusion}

Metropolitan areas are not just made up of people and firms, but of bricks and mortar as well. The growth and decline of a region's economy is mediated by the physical structure of the place. In declining areas, housing prices and incomes fall long before houses collapse. Until those houses collapse, population levels in cities remain high. Thus, urban populations decline slowly because housing and other infrastructure is durable.

\footnotetext{
${ }^{18}$ To be specific, a joint system of three equations with changes in population, real income per capita, and real housing prices as the dependent variables is estimated. The independent variables in each equation are the productivity shock (either predicted changes in labor demand or the share of college educated), an indicator for highly regulated areas, and the interaction between the two. Then, $\delta$ is calculated after imposing the nonlinear restriction that the ratio of the coefficient on the productivity shock in the housing price equation to the same coefficient in the wage equation must equal 0.15 .

${ }^{19} \mathrm{We}$ also experimented with using amenities rather than productivity differences to identify the parameters of the model. Specifically, we used mean January temperature to reflect amenity differences across locations. Because the climate has not changed much over the past decade, this variable is more naturally a determinant of the level of an amenity, rather than a change in the amenity. As long as mean January temperature is exogenous (i.e., not correlated with omitted variables), the coefficients based on estimating the model in levels of log population, house prices and incomes (i.e., equations (1)-(3)) should be the same as those from (1')-( $\left.3^{\prime}\right)$. The results from estimating these equations are not very precise, but they tend to match the predictions of the model qualitatively. While better amenity data and a clearer understanding of the channels through which the amenity variable impacts urban development might help improve these estimates, unobservable heterogeneity across metropolitan areas is likely to present a substantially larger problem in estimating these equations in levels.
} 
Not only is the pace of urban decline determined by the durability of residential structures, but urban expansion is determined by the elasticity of the supply of housing as well. In places where limited regulation and low density facilitate the construction of new homes, urban success is more likely to take the form of higher population levels. In contrast, in places with high density and high levels of regulation, urban success is more likely to leave population levels relatively unchanged while leading to higher levels of housing prices and income. Thus, it is impossible to understand that both Cambridge, MA, and Las Vegas, NV, were successful cities in the 1990s without recognizing that Cambridge faces an enormously restrictive building environment and Las Vegas does not.

In addition, this framework helps us better comprehend a variety of existing results in urban economics. For example, elastic housing supply in many markets is the natural explanation for why 'quality of life' studies report greater compensating differentials via wages in the labor market than via house prices in the land market (e.g., Blomquist, Berger, and Hoehn (1988); Gyourko and Tracy (1991)). In a related vein, this view of urban development also suggests that any other research that considers how differences in policy are capitalized in housing values should take heterogeneity in housing supply conditions into account. Because there can be no capitalization in places with a perfectly elastic supply of housing, the absence of capitalization does not necessarily imply anything about the effects of a policy. Another area of research that can be better understood by recognizing the role of the housing supply is the mean reversion of urban density and population documented by Eaton and Eckstein (1994). In particular, the neutral impact of density may reflect a positive influence of demand for the city that is offset by increasingly binding housing constraints. Other recent research investigating the impact of education on urban growth that finds differential effects for California areas (e.g., Glaeser and Shapiro (2003)) is best understood as reflecting inelastic supply in the housing market.

Overall, our results strongly suggests that scholars and policy makers must recognize that housing and real estate cannot be seen as research areas apart from the mainstream of 
urban economics. Those interested in urban and regional growth must think about housing markets, and in particular the nature of the housing supply. After all, firms in a region cannot expand employment without new homes to house new workers. Those who care most about real estate and housing markets are likewise dependent on understanding the urban markets that determine prices. Moreover, it is important for researchers from both disciplines to recognize the crucial role that the housing supply plays in creating differences in housing and labor markets across metropolitan areas. While our analysis focuses on the United States, its implications apply anywhere in the world where meaningful differences in the supply of housing markets exist. 


\section{Selected References}

American Institute of Planners (1976). Survey of State Land Use Planning Activity. Washington, DC: Department of Housing and Urban Development.

Alonso, William (1964). Location and Land Use. Cambridge, MA: Harvard University Press.

Bartik, Timothy (1991). Who Benefits from State and Local Economic Development Policies?, Kalamazoo: W.E. Upjohn Institute for Employment Research.

Blomquist, Berger, and Hoehn (1988). "New Estimates of the Quality of Life in Urban Areas", American Economic Review, Vol. 78 (March): 89-107.

Case, Karl and Christopher Mayer, "Housing Price Dynamics Within a Metropolitan Area," Regional Science and Urban Economics, Vol. 26.

Eaton, Jonathon and Zvi Eckstein (1994). "Cities and Growth: Theory and Evidence from France and Japan", Regional Science and Urban Economics, Vol. 27, no. 4: 443-474.

Glaeser, Edward and Joseph Gyourko (2005). "Urban Decline and Durable Housing", Journal of Political Economy, forthcoming. (2003). "The Impact of Zoning on Housing Affordability", Economic Policy Review, Vol. 9, no 2 (June 2003): 21-39, Federal Reserve Bank of New York.

Glaeser, Edward, Joseph Gyourko and Raven Saks (2005). "Why Is Manhattan So Expensive? Regulation and the Rise in House Prices", Journal of Law and Economics, forthcoming.

Glaeser, Edward and Albert Saiz (2003). "The Rise of the Skilled City", NBER Working Paper 10191.

Glaeser, Edward and Jesse Shapiro (2003). "Urban Growth in the 1990s: Is City Living Back?”, Journal of Regional Science, Vol. 43, no. 1: 139-165.

Gyourko, Joseph and Joseph Tracy (1991). "The Structure of Local Public Finance and the Quality of Life", Journal of Political Economy, Vol. 99, no. 4: 774-806.

Hwang, Min and John Quigley (2004). "Economic Fundamentals in Local Housing Markets: Evidence from U.S. Metropolitan Regions," Unpublished Working Paper, February 2004.

Kain, John (1962). "The Journey to Work as a Determinant of Residential Location", 
Papers of the Regional Science Association, IX: 137-160.

(1968a). "Housing Segregation, Negro Employment, and Metropolitan

Decentralization", Quarterly Journal of Economics, Vol. 82, no. 2: 175-197.

(1968b). "The Distribution and Movement of Jobs and Industry" in James Q.

Wilson (ed) The Metropolitan Enigma. Cambridge, MA: Harvard University

Press.

(2000). "Racial and economic segregation in US metropolitan areas," in Oxford Handbook of Economic Geography, Gordon L. Clark, Maryann P.

Feldman, and Meric S. Gertler eds. New York : Oxford University Press, 2000.

Kain, John and John Quigley. Housing Markets and Racial Discrimination: A Micro Economic Analysis. New York, NY: Columbia University Press.

Katz, Lawrence and Kenneth Rosen. "The Interjurisdictional Effects of Growth Controls on Housing Prices", Journal of Law \& Economics, Vol. 30, no. 1 (1987): 149-160.

Linneman, Peter, Anita Summers, Nancy Brooks, and Henry Buist (1990). "The State of Local Growth Management", Wharton Real Estate Center Working Paper No. 81, The Wharton School, University of Pennsylvania.

Malpezzi, Stephen (1996). "Housing Prices, Externalities and Regulation in the U.S. Metropolitan Areas," Journal of Housing Research, 7(2): 209-241.

Mayer, Christopher J. and C. Tsuriel Somerville (2000). "Land Use Regulation and New Construction," Regional Science and Urban Economics, Vol. 30, .

Mills, Edwin (1967). “An Aggregative Model of Resource Allocation in a Metropolitan Area”, American Economic Review, LVII(2): 197-210.

Moretti, Enrico (2004a). "Human Capital Externalities in Cities" in J.V. Henderson and J-F. Thisse (eds) Handbook of Urban and Regional Economics, Vol. 4. Amsterdam: North-Holland.

(2004b). “Workers' Education, Spillovers, and Productivity: Evidence from Plant-Level Production Functions", American Economic Review, Vol. 94, no. 3: $656-690$.

Muth, Richard (1969). Cities and Housing. Chicago: University of Chicago Press.

Peiser, Richard and Lawrence Smith (1985). "Homeownership Returns, Tenure Choice and Inflation", American Real Estate and Urban Economics Association Journal, Vol. 13 (Winter): 343-60. 
Poterba, James (1992). "Taxation and Housing: Old Questions, New Answers," American Economic Review, Vol. 82, no. 2: 237-242.

R. S. Means (2000a). Residential Cost Data, $19^{\text {th }}$ Annual Edition, R.S. Means Company. (2000b). Square Foot Costs, $21^{\text {st }}$ Annual Edition, R.S. Means Company.

Ruggles, Steven and Susan Brower (2003). "Measurement of Household and Family Composition in the United States, 1850-2000." Population and Development Review 29(1): 73-101.

Saks, Raven E. (2004). "Job Creation and Housing Construction: Constraints on Metropolitan Area Employment Growth". Working Paper.

Warner, Keen and Harvey Molotch. (2000). Building Rules. How Local Controls Shape Community Environments and Economies. Boulder, CO: Westview Press. 


\begin{tabular}{|c|c|c|}
\hline \multicolumn{3}{|c|}{$\begin{array}{c}\text { Table 1: } \\
\begin{array}{c}\text { Metropolitan Area Housing and Population Since 1970: } \\
\text { Levels and Changes }\end{array} \\
\end{array}$} \\
\hline \multicolumn{3}{|c|}{ Levels: Log Housing Units $_{t}=\alpha_{t}+\beta$ Log Population $_{t}+\varepsilon_{t}$} \\
\hline Year $(\mathrm{t})$ & $\begin{array}{c}\beta \\
\text { (standard error) }\end{array}$ & $\mathrm{R}^{2}$ \\
\hline 1970 & $\begin{array}{c}0.995 \\
(0.005) \\
\end{array}$ & 0.99 \\
\hline 1980 & $\begin{array}{c}0.997 \\
(0.005) \\
\end{array}$ & 0.99 \\
\hline 1990 & $\begin{array}{c}0.995 \\
(0.005) \\
\end{array}$ & 0.99 \\
\hline 2000 & $\begin{array}{c}0.981 \\
(0.005)\end{array}$ & 0.99 \\
\hline \multicolumn{3}{|c|}{ Changes: Log Change Housing Units $s_{t}=\alpha_{t}+\beta$ Log Change Population ${ }_{t}+\varepsilon_{t}$} \\
\hline Decade $(t)$ & $\begin{array}{c}\beta \\
\text { (standard error) }\end{array}$ & $\mathrm{R}^{2}$ \\
\hline $1970-1980$ & $\begin{array}{c}1.041 \\
(0.014) \\
\end{array}$ & 0.95 \\
\hline $1980-1990$ & $\begin{array}{c}0.861 \\
(0.018) \\
\end{array}$ & 0.88 \\
\hline $1990-2000$ & $\begin{array}{c}0.765 \\
(0.021)\end{array}$ & 0.81 \\
\hline
\end{tabular}

Note: Sample includes 316 metropolitan areas within the continental United States. Metropolitan area boundaries are based on their 1999 definitions, as issued by the Office of Management and Budget. 


\begin{tabular}{|l|l|l|l|}
\hline \multicolumn{5}{|c|}{$\begin{array}{c}\text { Table 2: } \\
\text { Housing Unit Growth } \\
\text { Cities With 100,000+ Residents }\end{array}$} \\
\hline \multicolumn{4}{|c|}{$1970-1980$} \\
\hline Bottom Five & \multicolumn{1}{c|}{ Top Five } \\
\hline St. Louis & $-16.5 \%$ & Colorado Springs & $64.1 \%$ \\
\hline Detroit & $-11.5 \%$ & Austin & $53.7 \%$ \\
\hline Cleveland & $-9.8 \%$ & Albuquerque & $52.2 \%$ \\
\hline Buffalo & $-6.0 \%$ & Stockton & $48.4 \%$ \\
\hline Pittsburgh & $-5.8 \%$ & San Jose & $46.4 \%$ \\
\hline \multicolumn{4}{|c|}{$1980-1990$} \\
\hline Bottom Five & \multicolumn{2}{c|}{ Top Five } \\
\hline Newark & $-16.9 \%$ & Las Vegas & $49.1 \%$ \\
\hline Gary & $-14.5 \%$ & Raleigh & $47.1 \%$ \\
\hline Detroit & $-14.0 \%$ & Virginia Beach & $46.9 \%$ \\
\hline Youngstown & $-10.0 \%$ & Austin & $39.3 \%$ \\
\hline Dayton & $-7.7 \%$ & Fresno & $37.7 \%$ \\
\hline \multicolumn{4}{|c|}{$1990-2000$} \\
\hline Bottom Five & \multicolumn{2}{|}{} \\
\hline Gary & $-10.5 \%$ & Las Vegas & $53.5 \%$ \\
\hline Hartford & $-10.3 \%$ & Charlotte \\
\hline St. Louis & $-10.2 \%$ & Raleigh \\
\hline Youngstown & $-9.6 \%$ & Austin \\
\hline Detroit & $-9.3 \%$ & Winston-Salem & $28.8 \%$ \\
\hline
\end{tabular}

Data source: Decennial censuses for 1970, 1980, 1990, 2000. Housing units defined to include owner-occupied and rental units. 
Table 3: Comparative Statics Results for the Effects of Productivity and Amenities on Urban Growth

\begin{tabular}{|l|l|l|}
\hline & Productivity $\left(\mathrm{A}_{\mathrm{j}}\right)$ & Amenities $\left(\mathrm{C}_{\mathrm{j}}\right)$ \\
\hline Ln(Population) & $\frac{\alpha}{1+\alpha \rho \delta}$ & $\frac{\alpha}{1+\alpha \rho \delta}$ \\
\hline Wages & $\frac{1}{1+\frac{1}{\alpha \rho \delta}}=\frac{\alpha \rho \delta}{1+\alpha \rho \delta}$ & $-\frac{1}{1+\alpha \rho \delta}$ \\
\hline Housing prices & $\frac{1}{\rho} \frac{1}{1+\frac{1}{\alpha \rho \delta}}=\frac{\alpha \delta}{1+\alpha \rho \delta}$ & $\frac{1}{\rho} \frac{1}{1+\frac{1}{\alpha \rho \delta}}=\frac{\alpha \delta}{1+\alpha \rho \delta}$ \\
\hline
\end{tabular}

Note. Each cell shows the effect of a 1-unit increase in either productivity or amenities on each of the variables in the left-hand column. See the text and equations (1)-(3) for details. 
Table 4: Effects of Productivity Shocks on Changes in Income/Capita, Housing Prices and Population, 1980-2000

\begin{tabular}{|c|c|c|c|}
\hline & $\Delta \operatorname{Ln}($ Population) & $\Delta$ Income/capita & $\begin{array}{l}\Delta \text { Housing } \\
\text { prices }\end{array}$ \\
\hline \multicolumn{4}{|l|}{ Labor Demand } \\
\hline Labor demand & $\begin{array}{c}1.28 * * \\
(.40)\end{array}$ & $\begin{array}{l}9240 * \\
(5148)\end{array}$ & $\begin{array}{c}-19294 \\
(74217)\end{array}$ \\
\hline Labor demand*High Regulation & $\begin{array}{l}-.63^{*} \\
(.37)\end{array}$ & $\begin{array}{c}-244 \\
(6903)\end{array}$ & $\begin{array}{l}\text { 190597** } \\
\text { (97074) }\end{array}$ \\
\hline \multicolumn{4}{|c|}{ Share of Population with Bachelors Degree ${ }^{1}$} \\
\hline Pop. Share & $\begin{array}{l}.091 * * \\
(.035)\end{array}$ & $\begin{array}{c}2223 * * \\
(425)\end{array}$ & $\begin{array}{c}17286 \\
(11271)\end{array}$ \\
\hline Pop. Share*High Regulation & $\begin{array}{l}-.063 \\
(.043)\end{array}$ & $\begin{array}{l}3161 * * \\
(1434)\end{array}$ & $\begin{array}{c}23764 * * \\
(8167)\end{array}$ \\
\hline \multicolumn{4}{|l|}{ Both productivity shocks } \\
\hline Both shocks (normalized) & $\begin{array}{l}.0040 * * \\
(.0012)\end{array}$ & $\begin{array}{l}45^{* *} \\
(12)\end{array}$ & $\begin{array}{c}195 \\
(197)\end{array}$ \\
\hline Productivity*High Regulation & $\begin{array}{c}-.0023^{*} \\
(.0013)\end{array}$ & $\begin{array}{c}66 \\
(48)\end{array}$ & $\begin{array}{l}851 * * \\
(293)\end{array}$ \\
\hline
\end{tabular}

Note. Each cell shows results from a separate regression with 118 observations. All regressions include a dummy variable for high regulation and a dummy variable for the 1990-2000 period. Standard errors are in parentheses and are clustered by state.

1. Share of population with a BA degree in initial year (1980 for 1980-1990 changes and 1990 for 1990-2000 changes). 
Figure 1: The Nature of Housing Supply and the Impacts of Demand Shocks

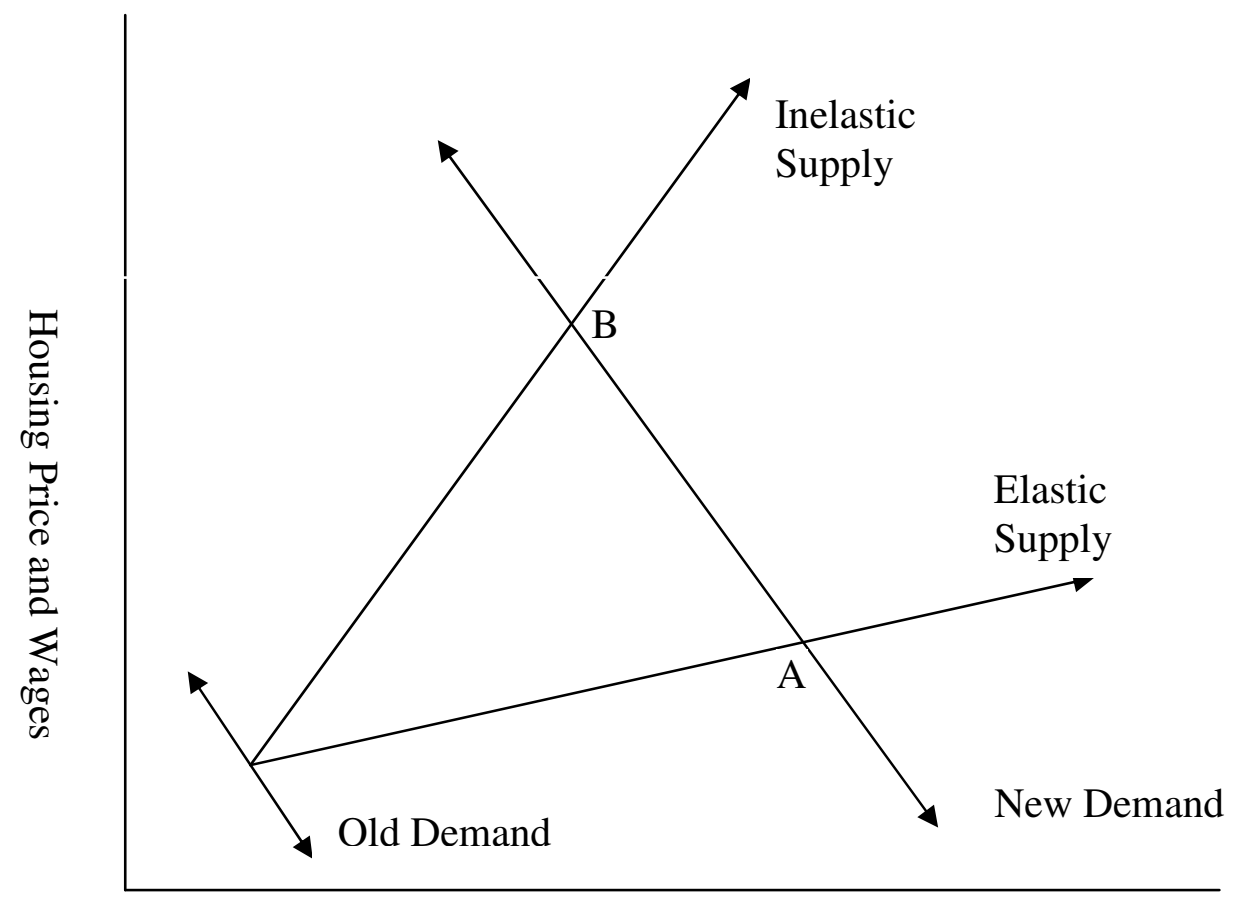

Number of Homes and Population 
Figure 2: Changes in Population and Vacancy Rates, 1990-2000

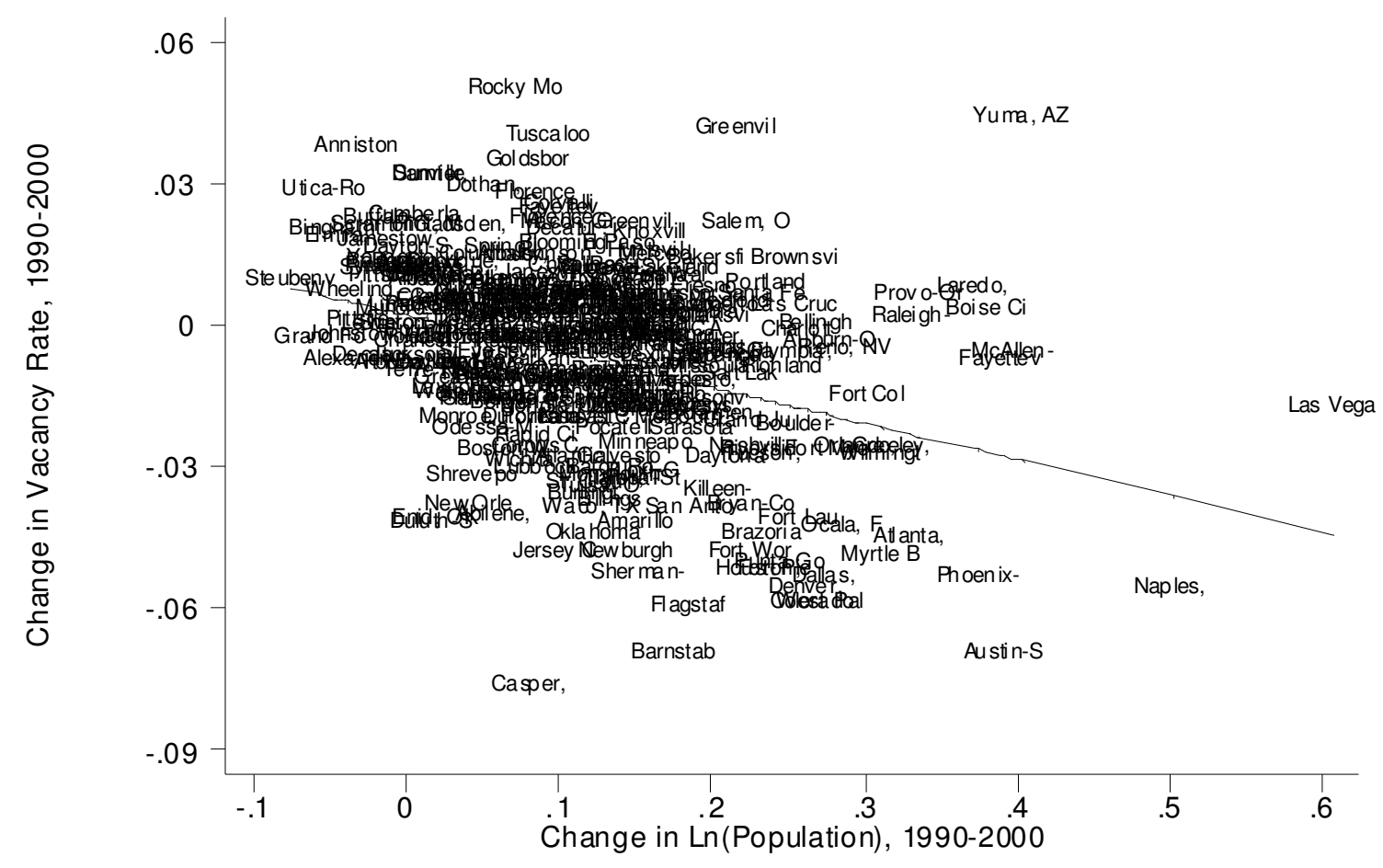


Figure 3: Metropolitan Area Population and Household Size, 2000

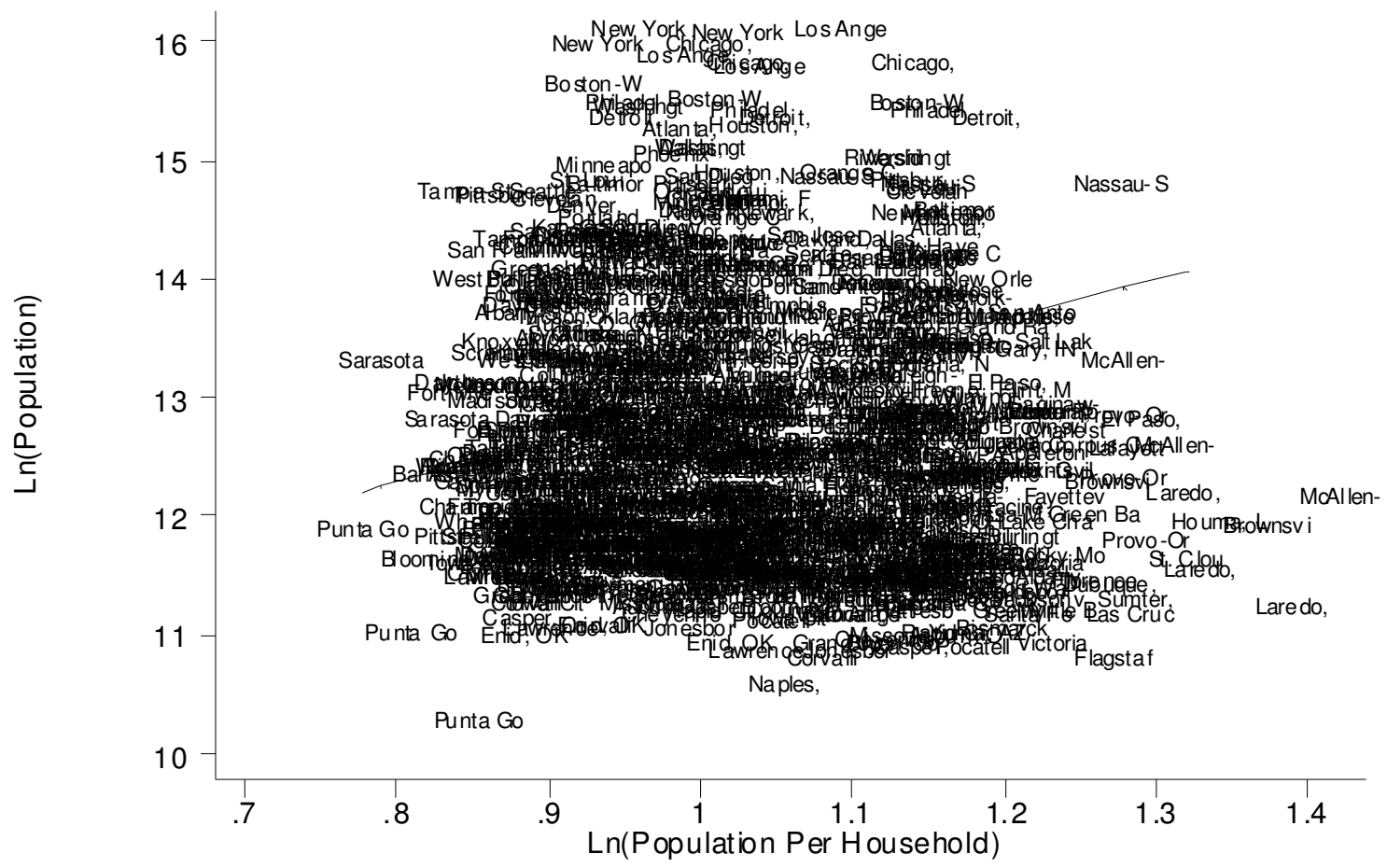

